\title{
Arauco Domado, Poema Manierista
}

Una terca adversidad afectó la vida de Pedro de Oña, y por centurias ha gravitado sobre su obra más famosa. Primero él nace por los dỉas en que su padre, el capitán español Gregorio de Oña, muere descuartizado a manos de los araucanos. Luego, como una forma de retribuir la protección que él y su familia reciben del virrey del Perú, don García Hurtado de Mendoza, Oña debe escribir un poema narrativo - el Arauco Domado- él, que estaba más dotado para componer poesỉa lírica. En seguida, publicado el poema, debido a la omisión de un trámite de formalidad oficial, la edición es incautada por la Inquisición y destruida casi en su totalidad. ${ }^{1}$ Críticos e historiadores no han perdonado a Oña el haber hecho de su poema una alabanza hiperbólica, como un intelectual a sueldo. A todo esto se agrega la condena de vivir el Arauco Domado, por una eternidad, bajo la sombra gigantesca de La Araucana.

Esto ha motivado una larga postergación de estudios críticos que tomaran en serio los valores intrínsecos del poema, estudios que superaran las descripciones históricas o filológicas.

En 1929, en la atmósfera de la conmemoración del tercer centenario de la muerte de Góngora, los estudios sobre Oña toman otro sesgo. Ese año el profesor chileno Eduardo Solar-Correa, en un ensayo decisivo instaura las bases de una nueva perspectiva sobre Oña, principalmente respecto del Arauco Domado. "Siempre tuvimos a Oña por un majadero", comienza diciendo en su ensayo; termina su estudio asi: "Saludamos en él al padre de la poesía chilena y americana, mas no lo sigamos imaginando como un anciano patriarca, grave y doctoral, sino como un patriarca joven -"sui generis"- en el que alentó un alma vehemente e imaginativa, enamorada de la belleza, de la mujer y de la última moda literaria."2 
El hallazgo más fecundo de Solar-Correa está en la afirmación del amor de Oña por "la última moda literaria." Es posible que el olvido de este sencillo rasgo de la personalidad del poeta haya sido la causa de la prolongada preterición de una crítica más genuina en torno a nuestro primer poeta.

De acuerdo a las indagaciones de José Toribio Medina en sus estudios sobre la imprenta en América, Pedro de Oña es el poeta más antiguo del continente. Hasta 1596, año de la aparición del Arauco Domado, no se había publicado ningún libro de versos de la jerarquía de este poema. Tal circunstancia histórica bastaría para justificar su incorporación en un programa de estudios acerca del desarrollo de la poesia hispanoamericana. Pero ahora hay otras razones más sólidas que apoyan ese criterio. Por una parte, el Arauco Domado es la obra de mayor aliento poético escrita por un seguidor de Ercilla. Por otra, el poema chileno es un ejemplo característico de la transición del estilo renacentista al estilo barroco en América.

Es un hecho establecido -como anota Emilio Carilla- que "los primeros contactos entre Góngora y América" no se produjeron sino al finalizar el siglo XVI, 3 probablemente cuando ya Oña terminaba su Arauco Domado, o lo llevaba muy adelantado. Por su parte, Rodolfo Oroz en la Introducción a su edición de El vasauro, poema barroco de Oña, sostiene: "La influencia de Góngora, a nuestro juicio, no es perceptible todavia en el Arauco Domado [...] Todas las peculiaridades estilissticas que adoptó Oña de Góngora aparecen sólo en sus últimas obras y, principalmente, en El vasauro."4

Sin embargo, Oña en su primera obra se muestra más preocupado por una expresión bastante elaborada, lujosa, morosa, vestida conforme el afán decorativista mitológico y pastoril que en el siglo XVII va a distinguir a los poetas del barroco pleno. La actitud creadora de Oña está orientada, más que hacia los contenidos representativos o reflexivos, hacia una visión lírica de los temas, hecho que dentro del cuadro literario de la época lo sitúa también en la línea de aquella poesǐa que derivará en el barroco. Tal estilo, apuntado ya con visible relieve en el Arauco Domado, tomará más tarde un rumbo declarado -como lo señala Oroz-, en sus poemas mayores, El vasauro, 1635, y el Ignacio de Cantabria, 1639. El gongorismo en este último poema, sobre todo en relación con el profuso empleo del hipérbaton, habìa sido ya destacado en 1662, por el Lunarejo, en su Apologético. 5

No debe olvidarse que el gongorismo es una culminación de un proceso cultista que, en España venǐa desenvolviéndose desde Juan de Mena (siglo XV), siguiendo en Garcilaso y Herrera, cuyos ecos lle- 
garon sin duda al Colegial chileno en Lima, juntamente con los clásicos latinos, y Petrarca y el Tasso. Dámaso Alonso observa que entre los años intermedios que van del renacentista Garcilaso al barroco Góngora se podrá ver "cómo no hay rasgo ninguno de los que se acumulan en el llamado gongorismo que no vaya apareciendo mucho antes, e intensificándose según pasan los años."6

Desde el punto de vista generacional, el estilo dominante en el Arauco Domado se ajusta a las ordenaciones del barroco divulgadas por Helmut Hatzfeld. Dentro del esquema propuesto por este autor, el poema de Oña cae en la categorĭa manierista (manierismo renacentista o renacimiento amanerado o pre-barroco), que en las letras hispanas cubre desde 1570 hasta 1600 . En apoyo de esta interpretación invocamos una de las formulaciones básicas de Hatzfeld:

Opino que, para el historiador de Literatura, también nos acercamos a la realidad si afirmamos que el estilo manierista y de transición representa el tanteo caracterǐstico del paso desde un estilo de época a otro. De acuerdo con ello, el Manierismo es como una cerca o espacio intermedio que puede concebirse como un Renacimiento tardio $\mathrm{y}$, asǐ, lo que se llama maniere son rasgos que modifican al Renacimiento puro o clásico y, al mismo tiempo, representan un estilo barroco naciente. El último Renacimiento, el amanerarse, se complace en alargar, acortar o exagerar las formas del gran Renacimiento, hasta convertirse en un Barroco primitivo cuando el ojo, acostumbrado a la línea clásica renacentista, ya no acierta a verla en aquellas formas distorsionadas." 7

Oña aparece, pues, en el Arauco Domado, atento al acontecer literario de su momento, "enamorado de la última moda literaria", la moda manierista.

De ahí una distinta vitalidad subyacente en el poema, que no veìa la crítica tradicional; de ahí su valor de testimonio de un estado de fermentación de los estilos poéticos en un instante límite de su evolución. De ahí también se infiere que el nacimiento de nuestra poesía está asociado a la nervadura del advenimiento del barroco en Indias.

Después de Ercilla, el Arauco Domado, escrito sobre el mismo tema, en octavas semejantes, en el siglo XVI, por un becario del Colegio Real de San Felipe y San Marcos de Lima, en alabanza del protector del poeta, aparecia a primera vista como una solemne majadería. Se daba por entendido era un mamotreto fabricado con 
materiales de segunda mano, con instrumentos lingüĭsticos fósiles, motivado no por un auténtico propósito estético, sino por una demanda mercenaria.

Pero "alli había algo que vivià", intuye Solar-Correa. "A medida que se adentra en la lectura vanse encontrando misteriosas armonias entre los versos del poeta y ese rostro alongado y fino que se prolonga en una barbilla suave, lisa, codiciable modelo para Domenico Theotocopuli."'(p. 51)

Alli habìa, en efecto, una vibración sutil que pasaba inadvertida a los ojos de la crítica derivada del retoricismo dieciochesco. Víctima célebre de esa secuela fue el propio Góngora. El redescubrimiento de este maestro proveyó de experiencia y de instrumentos rectificadores más eficaces en el análisis intrǐnseco $\mathrm{y}$, sobre todo, eliminó prejuicios seculares.

Solar-Correa, hombre de fina sensibilidad y de clarividente penetración, percibió una vinculación espiritual entre Oña y el Greco. Ahora vemos que lo que él vislumbraba era el manierismo común al estilo del poeta y del pintor. Aun el aparente desorden de ambos revela el desborde ya habitual en los nuevos ademanes estilísticos. En el Arauco Domado se ha desvanecido la maciza regularidad de $\mathrm{La}$ Araucana del mismo modo que en El entierro del Conde Orgaz del Greco ha desaparecido la simetría arquitectónica de La Escuela de Atenas o de la Disputa del Santo Sacramento de Rafael. "A Oña falta siempre, casi siempre -dice Solar-Correa- la mesura. Por eso, en estas hipérboles hay que ver un temperamento -un temperamento férvido e indisciplinado- y no simplemente el ansia mezquina de halagar al poderoso." (p. 58)

Pues lo que hay de indisciplinado, desmesurado, suntuoso y de ferviente subjetivismo en el Arauco Domado es signo innegable del acatamiento a la última moda literaria, vigente en el último cuarto del siglo XVI, en las letras occidentales.

El primer rasgo distintivo del Arauco Domado, que aparece a simple vista es el tipo de estrofa usado allí. Y como el oîdo del lector estaba habituado a la octava real de Ercilla, la octava de Oña se oúa "menos solemne y más graciosa...", como observó Menéndez Pelayo."8 Compárese:

Chile, fértil provincia y señalada

en la región antártica famosa, de remotas naciones respetada por fuerte, principal y poderosa; la gente que produce es tan granada, 
tan soberbia, gallarda y belicosa, que no ha sido por rey jamás regida ni a extranjero dominio sometida. (La Araucana, canto I.)

La fuente que con saltos mal medidos por la frisada, tosca y dura peña en fugitivo golpe se despeña llevándose de paso los oídos; en medio de los árboles floridos y crespos de la hojosa y verde greña, enfrena el curso oblicuo y espumoso haciéndose un estanque deleitoso. (Arauco Domado, canto V.)

En la octava real, la rima alternada de los seis primeros versos crea un andar rectilineo de pasos regulares que se detienen abruptamente en los pareados finales. La composición se conforma a la solemne elegancia y contención clásicas, observadas como una norma general del Renacimiento. En el ejemplo de Oña, en cambio, la diversificación de la distribución de la rima y la nueva colocación del énfasis acentual -"la nueva trabazón de las cadencias", dice Oña en el Prólogo- rompe la rigidez antigua, y produce sinuosidad y suavidad en el correr de los versos, del mismo modo que hacen los pintores (Tintoretto, el Veronés, el Greco) al incorporar la profundidad y la curvatura del modelado a la antigua pintura plana.

La estrofa de Oña había sido usada alguna vez, en el siglo XVI, por Diego Hurtado de Mendoza en composiciones poéticas de escasa difusión, porque él se distinguió más bien en la prosa histórica. Conocida o no por el poeta chileno, es sintomático que él la haya preferido no, como se ha dicho, por el mero prurito de introducir una nota distinta de La Araucana, sino en obedecimiento al impulso de buscar una novedad formal más genuina. "La nueva estrofa -dice Caillet-Bois- era un rasgo de osadía no sólo frente a su modelo inmediato, sino que rompía con ella una tradición de forma en el poema del Renacimiento."9 Cuando Oña escribe su Arauco Domado estaba inmerso en el ámbito renovador de la época.

Pero la novedad de la estrofa no es el único rasgo manierista en el Arauco Domado. Lo es, principalmente, la perspectiva poética ante el tema ercillano, generada en un poeta provisto de una nueva sensibilidad, una sensibilidad y una concepción del mundo determinadas por nuevas condiciones culturales y artísticas, dominantes en el orbe 
hispánico de fines del siglo XVI. El joven Oña, de 25 años de edad, no tuvo tiempo para "contaminarse" en las aguas puras del Renacimiento pleno. Su oficio se gesta en el transcurso del período de transición del Renacimiento al Barroco. Asimiló la moda literaria y la practicó con entusiasmo. Enrique Anderson-Imbert ha sido el único crítico que se ha arriesgado a sustentar la existencia concreta de alardes barrocos en algún momento del Arauco Domado. Señala un ejemplo, el del pasaje en que los españoles cortan las manos a Galvarino. Al confrontar dos estrofas de La Araucana, canto XXII, y otras dos del Arauco Domado, canto XII, sobre el mismo tema, él destaca la "tranquilidad clásica" de Ercilla y la complejidad, angustia y dinamismo barrocos de Oña. 10

La prueba de Anderson-Imbert es concluyente. El pasaje elegido ilustra cómo el manierista -asî sucede con el Greco- suele alcanzar extremos que coinciden con el barroco. De ahí que, debido a esta inquietante vecindad no todos los teóricos del barroco miran con buenos ojos el concepto de manierismo como entidad estilística autónoma.

Una determinación y análisis de los elementos manieristas en un cuerpo de dieciséis mil versos, como el Arauco Domado, llevarìa largo tiempo, espacio y acaso enfado. Pero reparemos en algunos puntos de la obra que sostengan las postulaciones expuestas.

Es obvio que el poeta se halla más cómodo y gozoso en los momentos en que puede desplegar su visión subjetiva, que en los momentos de información histórica o descripción épica. Así, al referir las circunstancias del nombramiento de García Hurtado de Mendoza como jefe de la expedición a Chile, Oña emplea sus mejores energías poéticas $y$ dedica íntegramente el canto primero, a la animada descripción de los preparativos expedicionarios en Lima, del embarque en el Callao y de la navegación hacia el Sur. Todas estas actividades de rutina en la Conquista y de escaso valor histórico proveen al poeta de óptima motivación para crear unos cuadros impresionistas brillantes y de un dinamismo avasallador. Ercilla, participante del episodio histórico, despacha estas contingencias en un sector del canto XIII, registrando principalmente datos documentales, "considerando ser la historia verdadera y de cosas de guerra", como advierte en el "Prólogo del autor". Tal se ve al narrar la concurrencia de soldados venidos de fuera de Lima, a enrolarse en la campaña:

Del apartado Quito se movieron gentes para hallarse en esta guerra; 
de Loja, Piura, de Jaén salieron, de Trujillo, de Guánuco y su tierra;

de Guamanga, Arequipa concurrieron gran copia, y de los pueblos de la sierra, la Paz, Cuzco y los Charcas bien armados bajaron muchos pláticos soldados.

(La Araucana, canto XIII.)

Ercilla enumera cada uno de los diversos lugares del virreinato desde donde acudieron soldados bien armados y experimentados, al llamado del virrey. Vienen en cierto orden, no se derraman, unos de Quito y Loja en Ecuador; otros de Arequipa en el Sur, aquéllos del Cuzco y la Paz en la sierra.

Por su lado, Oña sintetiza el hecho como un desbordamiento de sierras y valles que se despliega ante los ojos pasmados de un espectador residente en la ciudad de los Reyes:

Bajaron de la sierra y de los valles

tal número de gente forastera, que dar lugar a tantos no pudiera, a no tener el pueblo tantas calles;

andaban por allǐ gentiles talles, la gala y presunción por dondequiera, soldados valentǐsimos y nobles, mirtos en condición, en fuerza robles. (Arauco Domado, canto I.)

Al poeta chileno no le preocupan las objetividades históricas y geográficas, que Ercilla precisa con perfiles nítidos, en una enumeración rica en información, pero estilî́sticamente estática. Oña enlaza y relaciona los elementos heterogéneos en una composición que no deja espacios vacios. Recuérdese el Greco, en que las figuras y la utilería parecen obedecer a un poderoso impulso dinámico único. El torrente de "la gente forastera" se filtra por las diversas arterias de la capital del virreinato; es una multitud que vamos apreciando gradualmente, a medida que se aproxima. Al final podemos distinguir sus "gentiles talles", sus galas y aun su condición personal, fina como mirto, fuerte como roble, reflejada tal vez en su comportamiento, en sus gestos y en su rostro. Más que soldados de oficio, semejan personajes de selección, con los atributos básicos del hombre ideal del Renacimiento. Estos son los héroes que han de formar la legión que dirigirá el héroe que se exalta en el Arauco Domado.

La fantasía de Oña no estaba sofrenada, pues por las limitaciones del cronista y de la mentalidad que vigila la regularidad y el balance de masas informativas y líricas, requisito de la mesura clásica. 
Por eso puede regodearse libremente en la pintura de Lima mediante el movimiento mercantil que le imprime la demanda de artículos, vestuarios y pertrechos con que se preparan los hombres para una prolongada campaña en un paǐs lejano y ciertamente lleno de peligros. La ciudad adquiere con este motivo la vibración y colorido de una feria, "ya toda Lima es tráfago y bullicio."

Ya desde los balcones descogidas tremolan con el aire las banderas y quiérenlo abrazar de mil maneras con verse de sus manos sacudidas; mil aguas hacen cotas enlucidas, rayos de fuego brotan las cimeras; ya la pajiza pluma y roja banda jugando por cabeza y pechos anda.

El panorama brinda una mancha impresionista, destinada únicamente al halago de la vista. Primero el juego de las banderas y el aire, que inaugura, desde lo alto, la atmósfera de color, con el retruécano en que las banderas son el factor activo, y no el aire invisible: son ellas las que "quiérenlo abrazar de mil maneras". El arco iris que forman se pormenoriza en la segunda sección de la octava, en reflejos metálicos y cromos, con predominancia de los colores españoles, el amarillo en la cabeza y el rojo cruzando el pecho de los soldados.

La mancha trazada velozmente reviste en la octava venidera, una configuración de sistema:

Ya salen de las tiendas los brocados

y sedas mil distintas en colores;

ya sacan vistosǐsimas labores,

vestidos y jaeces recamados;

por otra parte petos acerados,

y adargas, ya de cuadros, ya de flores;

venablos, lanzas, picas y jinetas,

mosquetes, arcabuses y escopetas.

El nexo anafórico "ya", con su porfiada persistencia, mantiene la tensión de la corriente de los elementos y de la agitación, desencadenada por los gestos entusiastas de las banderas. Ahora los objetos se van clasificando y recuperando los perfiles amagados por sus propios valores pictóricos. Telas, adornos, trajes; luego armaduras 
y escudos y, finalmente, armas, primero lanzas y, por último, armas de fuego. El conjunto sugiere asî una conformación de desfile.

Verdad es que la reciedumbre que se espera de un poema épico a la manera renacentista, no aparece por parte alguna, ni aun cuando el poeta se esfuerce más adelante, en sustentar que "tal trápala, tropel y baraúnda" no se vio ni en la Cartago de las guerras púnicas. Pero, eso sí, la vitalidad lírica, el sensualismo cromático y lineal, el ritmo y las dinámicas asociaciones de imágenes, virtudes propias del manierismo, son categóricos.

Ahora bien, levantada la decoración con el gran plano de Lima en movimiento, al que se monta otro telón de amplio fondo marino, el del Callao, ya puede hacer su entrada la figura central del poema. El suntuoso escenario crea un ámbito de prestigio que justificaría el tono laudatorio. Pero en tiempos del Arauco Domado no se daba todavia por entero la audacia de la hipérbole usada como recurso normal. De ahí que el poeta manierista prepare prolija y gradualmente el último instante del proceso:

Partido, pues, de Lima el mozo bello

encaminó sus pasos a la playa

y en medio su escuadrón haciendo raya

a toda perfección echaba el sello;

sumo placer causaba a todos vello,

sumo pesar también de que se vaya;

todo el Pirú su pérdida lamenta

y Chile su ganancia representa.

Los héroes renacentistas son fuertes, invencibles, incansables, nobles, justos, apasionados y dueños ya de una ingente experiencia; pero no se declara su belleza física. Una de las constantes del nuevo estilo es la de la belleza puesta sobre el vigor. El personaje del Arauco Domado es bello y joven, naciente. Está colocado al comienzo de una empresa magna. Sale de Lima como resumen y compendio de los valores estéticos de la ciudad, ya descritos, y como el efluvio de la esencia imperial atrapada en las banderas tremolantes. Ese impulso germinal se enlaza con la situación real: en medio del grupo informe de guerreros, recién constituido, el jefe actúa como un demiurgo de cuyos gestos y la aprobación de su "sello" brotan el orden y lo perfecto. Su prestigio se viene construyendo sólidamente. Las antìtesis de los cuatro versos finales ("sumo placer" - "sumo pesar", "el Pirú su pérdida lamenta" - "Chile su ganancia representa") refuerzan la 
complejidad de las virtudes que hacen altamente amable y admirable al héroe, a punto de entrar en la ruta mítica de la caballería andante. $\mathrm{Y}$ así la exaltación hiperbólica -llevada a una altura superior al sol naciente- atenúa su férvida extremosidad:

No sale tal el Hijo de Latona

\section{cual muestra don Hurtado su persona.}

Los rasgos manieristas anotados corresponden al canto primero del Arauco Domado. Pero el sistema es visible, acaso con mayor notoriedad, en el resto del poema, y esto es lo que le confiere su compacta unidad, asi como sus valores y sus debilidades. Un enjuiciamiento adecuado de esta obra debe, pues, partir de este supuesto.

University of Iowa

JULIO DURAN-CERDA

\section{NOTAS}

1. A este delito de forma contra las reglas del Santo Oficio, se suma otro más sustancial y decisivo, que había sido subestimado por los capitulares encargados de autorizar la publicación del poema. Se trata de la exposición de la rebelión de la ciudad de Quito, irritada por la implantación de pesados impuestos, y luego sometida a una sangrienta represión armada. El hecho es contemporáneo al gobierno de don Garcĭa, y permite calificar el comportamiento desaforado de algunos personajes de la época, que aparecen moralmente menoscabados. El suceso histórico es el contenido del sueño que narra la india Quidora, a través de los cantos XIV, XV y XVI, del Arauco Domado, amplitud de desarrollo que evidencia el efecto intenso que el episodio tuvo en la sensibilidad del poeta. (Véase: J.T. Medina, "Proceso de Pedro de Oña con motivo de la publicación del Arauco Domado", en Biblioteca hispano-chilena, 1523-1817, tomo I, Santiago de Chile: Casa del Autor, 1897, pp. 47-74.)

2. Eduardo Solar-Correa, "El patriarca de la poesia chilena. Pedro de Oña", Atenea, Concepción, Chile, VI (1929), No. 56, pp. 5-13, y No. 57, pp. 162-173. - Reproducido bajo el título de "Pedro de Oña. 1570-1643? " en Semblanzas Literarias de la Colonia, Santiago de Chile: Editorial Nascimento, 1933, pp. 49-98. (Las citas subsiguientes pertenecen a esta edición.)

3. Emilio Carilla, El gongorismo en América, Buenos Aires: Facultad de Filosofia y Letras de la Universidad de Buenos Aires, 1946, p. 23. Carilla en esta materia se apoya en las ordenaciones de recibos, listas de embarque de libros y protocolos puestos a nuestro alcance merced a la acuciosidad de Irving $\mathrm{A}$. Leonard. 
4. Pedro de Oña, El vasauro, Introducción y notas por Rodolfo Oroz, Santiago de Chile: Prensas de la Universidad de Chile, 1941, p. XCVII.

5. Juan de Espinosa Medrano, "Apologético en favor de D. Luis de Góngora", Revue Hispanique, tome LXV, Numéro 148 (Décembre, 1925), pp. 458-459.

6. Dámaso Alonso, Góngora y el "Polifemo", vol. II, Madrid: Editorial Gredos, 1961, p. 69.

7. Helmut Hatzfeld, Estudios subre el Barroco, Madrid: Editorial Gredos, 1964, p. 54.

8. M. Menéndez-Pelayo, Antología de poetas hispanoamericanos, tomo IV, Madrid: Est. Tip. "Sucesores de Rivadeneyra", 1895, p. XVII.

9. Julio Caillet-Bois, "Dos notas sobre Pedro de Oña", Revista de Filología Hispánica, año IV, No. 3 (Julio-Septiembre, 1942), p. 269.

10. Enrique Anderson-Imbert, "El renacentista Ercilla y el barroco Oña", en Los grandes libros de Occidente $y$ otros ensayos, México: Ediciones de Andrea, 1957, pp. 45-47. 
